\title{
Serological and Hematological Study of Toxoplasmosis in Blood of Newly Born Babies
}

\author{
Khairy A. Dawood Assit ${ }^{1}$, Ruaa A. Talib ${ }^{2}$, Hasanain Falah ${ }^{3}$ \\ ${ }^{1,2,3}$ Dept. of Pathological Analysis/ College of Al-Mustaqbal University \\ E-mail: khairy.abdulla@mustaqbal-college.edu.iq
}

\begin{abstract}
Serological identification and blood pictures were done for specific IgM and IgG.10\% of cases were positive IgM of Toxoplasmosis because have $10 \mathrm{IU} / \mathrm{ml}$ (mean) in comparison with control group were $0.11 \mathrm{IU} / \mathrm{ml}$ (mean). On other hand $20 \%$ of diagnosed cases were positive IgG of Toxoplasmosis because have $11 \mathrm{IU} / \mathrm{ml}$.Two cases were followed for their history one from group IgM and other IgG, first one suffered from three abortion and now have five child three of them healthy while two have congenital defects. Second case (IgG positive) have four abortion and now have three child, two healthy and one have congenital defect. Blood picture reveal $40 \%$ suffered from Normocytic anemia, these cases classified to three groups, first Toxoplasma group 30\% (positive in ELISA test). Second group (Unknown causes), these cases not only normocytic anemia also have high total leukocytes $17 \times 10$ (mean) and high MCV (103 ft). Third group have low MCV $78 f t$.
\end{abstract}

Keywords: Toxoplasmosis, Neonatal Infection, Toxoplasma Gondii.

\section{Article Information \\ Received: Augest 15, 2021; Revised: Augest 27, 2021; Online: September, 2021}

\section{INTRODUCTION}

Congenital Toxoplasmosis occur when Toxoplasma gondii crosses the placenta barrier from the mothers blood. Most neonatal infection are asymptomatic but some causes death or disability to newborns ( Duby, J. 1995, Jones J, Lopez A, Wilson M. 2003 \& Remington, J. et al., 2010).

Guerina , N. et al (1994) published data on neonatal serologic screening and early treatment for congenital toxoplasmosis in new England region. In Norway Jenum ,P (1998). Studied the incidence of Toxoplasma gondii infection in 35, 940 pregnant women and pregnancy outcome for infected women.

T. gondii can cause a congenital infection when women are infected during pregnancy or less commonly when women are infected during pregnancy or less commonly when chronic infection become disseminated due to iminune compromising or reinfections (Gavinet M. F. et al., 1997).

If congenital toxoplasmosis is not treated sever or fatal squelae can occur. Fetal transmission rate depend on three concomitant factors : maternal parasitemia , gestational age at infection and maternal immune response to T.gondii (jones $\mathrm{J} \mathrm{L}$. et al., 2001). Nimri ,L. et al (2004). Published a modified research work on detection of $\mathrm{T}$. gondii DNA and specific antibodies in high risk pregnant women. The most frequently observed clinical signs of congenital Toxoplasmosis are premature birth, low birth weight, retinocoroiditis, squint, jaundice, cerebral calcification, hydrocephalus and hepatosplenomegaly (Paquet C. and Yudin M. H. 2013) . Figueiro -Filho , E.A. and Lopes 
,A.H. (2005). Studied pregnant women serologically and found 7 . gondii $\mathrm{IgG}$ occurrence ranging from $31 \%$ to $91 \%$ in two different states in brazil . the risks of fatal infection are directly associated with disease prevalence in the population and with number of women in fertile age not infected and susceptible to infection during pregnancy, thus the importance of preventive actions should be emphasized as well as the early diagnosis and treatment to prevent or attenuate fetal infection ( Foulon W.1992, Gavinet M F et al., 1997\&Matrin, F.2000).

Moura F L et al (2007) worked a survey of pregnant and postpartum women in the same population in Niteroi, showed that a significant number $(41.5 \%)$ of susceptible women can acquire $\mathrm{T}$. gondii during pregnancy, these susceptible patients are at risk of transmitting the parasite to their offspring through vertical transmission. The present study, was done randomly by testing blood samples were taken from umbilical cord of newly born babies, serologically for identification of $\mathrm{T}$, gondii infection and hematological changes.

\section{MATERIALS AND METHODS}

Hundred pregnant women attended to the maternity and children hospital of Hilla on January 2017, Blood sample were collected from umbilical cord of newly born babies, these samples were hundred divided in two tubes, one with anticoagulant for study blood pictures, while other tube without anticoagulant for isolation serum to identify Toxoplasmosis by direct method of ELISA , the assays for toxoplasma $\operatorname{IgM}$ and $\mathrm{IgG}$, briefly a $6 \mathrm{~mm}$, and specimen was tested by an IgM specific enzyme linked immunosorbent ássay with a reported a sensitivity, therefore control group rang 0.1-0.9 IU/ml (negative) , While over $5 \mathrm{IU} / \mathrm{ml}$ (positive) for toxoplasmosis, in between these (suspicion), (Schmidt, S. et al.,2012).

Blood pictures were done in hematology laboratory of hospital by using blood analyzer. The results of these tests included complete blood picture of each sample.

Serological test confirmed the presence of toxoplasma IgM or IgG and accompanied with history of mother must be treated immediately.

\section{RESULT}

Results of blood analysis for umbilical cord blood divided to three groups depend on picture. Normocytic (1) group, Normocytic (2) group, Toxoplasmosis group.

Toxoplasmosis: These group of cases where identified serologically direct method of ELISA , $10 \%$ of cases where positive to ELISA test for $\mathrm{T}$. gondii because have 10 $\mathrm{IU} / \mathrm{ml}$ (mean) of $\mathrm{IgM}$, in comparison with control were $0.11 \mathrm{IU} / \mathrm{ml}$, therefore these cases consider acute cases.

On other hand $20 \%$ of dignosed cases were positive for toxoplasmosis because $\mathrm{IgG}$ which is specific for T. gondii was $11 \mathrm{IU} / \mathrm{ml}$ (mean), therefore these cases are chronic cases. The most prominent result of blood picture of Toxoplasmosis cases showed increase in total number of leukocytes 15.2$24.1 \times 1000$ ( rang) table (1) Fig. 1.

Two cases of toxoplasmosis were followed for their history, case number (2) who have IgM $10 \mathrm{IU} / \mathrm{ml}$, history of these was suffered from three abortion in previous time and now have five children, three of them were healthy while other two have congenital defects. Case number (4) has IgG $11 \mathrm{IU} / \mathrm{ml}$ suffered from four abortions and now has three children, two healthy and one have congenital defect.

\section{Normocytic 1:}

Blood analysis revealed this group of cases was suffer from normocytic anemia with unknown cases with increase in total number of leukocytes 14.5-21.9 x1000 (mean) Table (1) Fig 1.

Table (1) Fig 3 demonstrated the mean corpuscular volume (MCV) increased 101 107 fil (rang), $103 \mathrm{ftL}$ mean while the control 81-96 fL. These cases also showed increased in (MCHC) mean corpuscular hemoglobin concentration, the range was 34.1-37.6 with a mean 35.9 in comparison with control 31.8 35.4, Fig. (2). As well as hemoglobin quantity was in between 14.1- $21.9 \mathrm{gm}$ with a mean 
$17.1 \mathrm{gm}$ in comparison with control $12.5-16$ gm Table (1).

\section{Normocytic 2:}

These group were have normal total number of leukocytes count $7.111 .3 \times 1000$ with a mean $8 \times 1000$, but MCV decreased than normal 72-81 ftL , 78 mean while control 81$96 \mathrm{ftL}$. MCVC was slightly increased with range 34.4- 37.6 mean 36.1, while control 31.8-35.4 . Hemoglobin result was with in the normal range, Fig (3).

Table (1) Represent the most prominent changes in blood picture

\begin{tabular}{|c|c|c|c|c|c|c|c|c|c|c|c|c|}
\hline \multirow[b]{2}{*}{$\begin{array}{l}\text { Group of } \\
\text { Causes }\end{array}$} & \multicolumn{3}{|c|}{ WBC X10 3} & \multicolumn{3}{|c|}{ MCV FIL } & \multicolumn{3}{|c|}{$\mathrm{MCHC}$} & \multicolumn{3}{|l|}{$\mathrm{HB}$} \\
\hline & $\begin{array}{l}\text { Ran } \\
\mathrm{g}\end{array}$ & $\begin{array}{l}\text { Mea } \\
\mathrm{n}\end{array}$ & Con. & $\begin{array}{l}\text { Ran } \\
\mathrm{g}\end{array}$ & $\begin{array}{l}\text { Mea } \\
n\end{array}$ & Con. & $\begin{array}{l}\text { Ran } \\
\mathrm{g}\end{array}$ & $\begin{array}{l}\text { Mea } \\
\mathrm{n}\end{array}$ & Con. & $\begin{array}{l}\text { Ran } \\
g\end{array}$ & $\begin{array}{l}\text { Mea } \\
\mathrm{n}\end{array}$ & Con. \\
\hline $\begin{array}{l}\text { Positive } \\
\text { Toxoplas } \\
\text { mosis }\end{array}$ & $\begin{array}{l}15.2- \\
24.1\end{array}$ & 20.2 & $4-11$ & $\begin{array}{l}96.4- \\
104\end{array}$ & $\begin{array}{l}100 . \\
9\end{array}$ & $\begin{array}{l}81- \\
96\end{array}$ & $\begin{array}{l}33.9- \\
36.4\end{array}$ & 35.5 & $\begin{array}{l}31.8- \\
35.4\end{array}$ & $\begin{array}{l}14- \\
18.7\end{array}$ & 15.8 & $\begin{array}{l}12.5- \\
16\end{array}$ \\
\hline $\begin{array}{l}\text { Group } \\
1\end{array}$ & $\begin{array}{l}14.5- \\
21.9\end{array}$ & 17.2 & $4-11$ & $\begin{array}{l}101- \\
107\end{array}$ & 103 & $\begin{array}{l}81- \\
96\end{array}$ & $\begin{array}{l}34.1- \\
37.6\end{array}$ & 35.9 & $\begin{array}{l}31.8- \\
35.4\end{array}$ & $\begin{array}{l}41.1- \\
21.9\end{array}$ & 17.1 & $\begin{array}{l}12.5- \\
16\end{array}$ \\
\hline $\begin{array}{l}\text { Group } \\
2\end{array}$ & $\begin{array}{l}7.1- \\
11.3\end{array}$ & 9.2 & $4-11$ & $\begin{array}{l}72- \\
81\end{array}$ & 78 & $\begin{array}{l}81- \\
96\end{array}$ & $\begin{array}{l}34.4- \\
37.6\end{array}$ & 36.1 & $\begin{array}{l}31.8- \\
35.4\end{array}$ & $\begin{array}{l}11.8- \\
13.5\end{array}$ & 12.7 & $\begin{array}{l}12.5- \\
16\end{array}$ \\
\hline
\end{tabular}

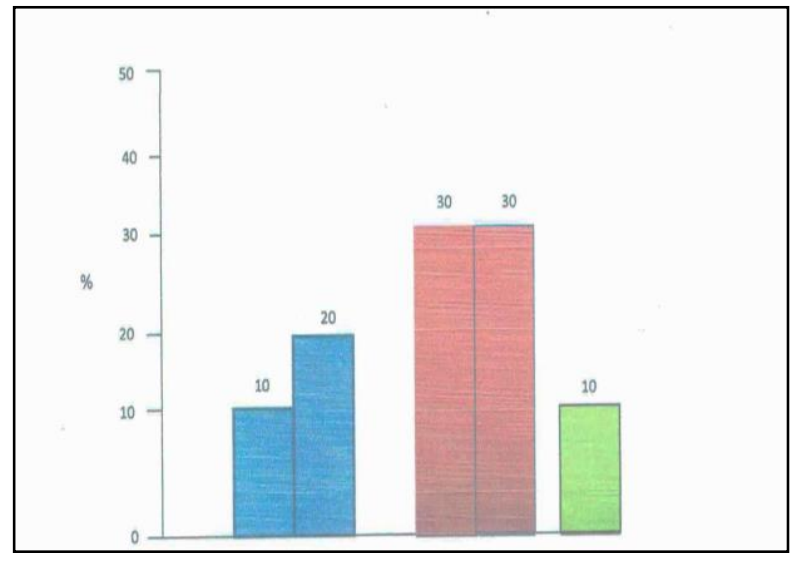

IgM IgG Normocyte healthy Fig (1): show the results of blood analysis and ELISA.

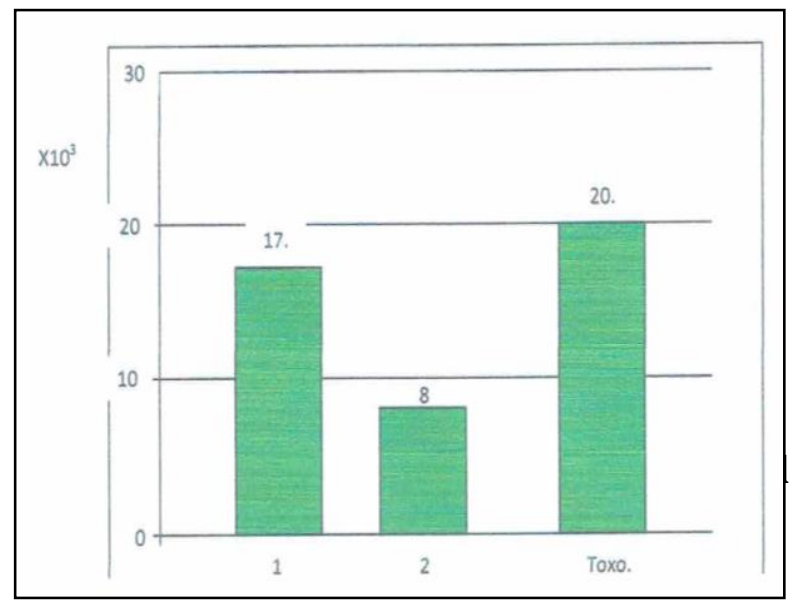

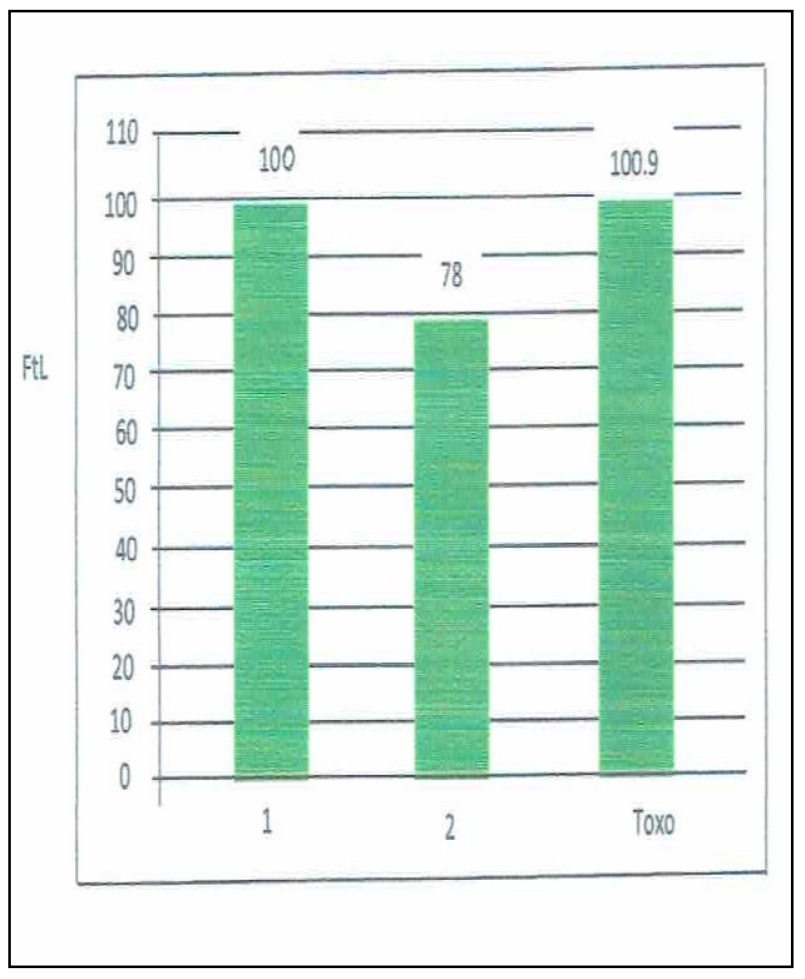

Fig (3) Comparison among the results of mean corpuscular volume (MCV) for three groups.

\section{DISCUSSION}

Many researchers work on toxoplasmosis and especially on congenital toxoplasmosis 
but from different aspects . Murwa, J. (2010) worked on toxoplasmosis serologically , 30\% worked on toxoplasmosis serologically , 30\% of $\operatorname{IgG}$ were positive by ELISA test, these results similar of these research but not IgM not recorded in comparison with present $10 \%$, this variation depend several factors such as hosts, intermediate and final hosts and its distribution, susceptibility of women, or ingestion of undercooked meat (conimon in IRAQ) during pregnancy, as well as contact with cats or its fecal materials in gardens.

This research proved IgM production and this mean acute infection is present because it is produced during fitst month of infection .As well as several abortions from the same mother this represent reinfection and chronic disease can be reactivated to acute stage.

Two cases were chosen randomly one from IgM group and second from IgG group, first case have child with congenital toxoplasmosis (chorioretinitis ) while second case have one child with congenital toxoplasmosis (mental retardation and chorioretinitis ). These results nearly similar to the results presented by Nicholas G. G. et al (1994) tested 50 women 19 who positive for $\operatorname{IgM}$ and $\operatorname{IgG} 38 \%$ (present work 40\%, 30\% $\operatorname{IgG}, 10 \% \operatorname{IgM}$ ( .

Normocytic anemia, it is accompanied with chronic disease (Robbins et al.,2008), therefore some cases of toxoplasmosis (chronic cases) have normocytic anemia , while other cases ( not Toxoplasma but unknown causes) may be have chronic diseases as kidney diseases, cancer, rheumatoid arthritis , thyroiditis.

\section{CONCLUSION} Hilla.

1- Toxoplasmosis is endemic disease in

2- Percent of women have positive reaction for IgG of Toxoplasmosis was $30 \%$, chronic stage of disease.

3- Percent of women have positive reaction for IgM of Toxoplasmosis

was $10 \%$, acute stage of disease.

4- $30 \%$ of cases of toxoplasmosis were suffered from Normocytic anemia.

$5-30 \%$ of women have Normocytic anemia but without Toxoplasmosis (unknown) causes.

6- $10 \%$ of women were normal healthy depend on blood picture.

\section{RECOMMENDATIONS:}

Congenital Toxoplasmosis serious problem, therefore prevention and control needed as soon as possible as follows:

1- Primary prevention is characterized by educational programs and public health to avoid infection because two cases were followed randomly, these women were uneducated.

2- Secondary prevention consists of serological screening during prenatal care to detect and treat acute infections by $T$. gondii , thus reducing the squeal caused by congenital toxoplasmosis.

3- Tertiary prevention is focused on the newborn, in which newborns with subclinical congenital Toxoplasmosis are treated in order to prevent further complications, especially ocular and risk of reactivation.

\section{REFERANCE}

1. Dubey, J.P. (1995). Toxoplasma gondii. Medical microbiology Chapter 84:pp:350.

2. Figueiro-Filho, E., Lopes, A., Senefonte, F., Souza,Junior, V.\& Botelho, C. (2005). Toxoplasma gondii: Study the Frequency of vertical transmission diagnosis of Maternofetalis. Rev.Bras. Ginecol. Obestet.27:442-9.

3. Foulon, W.(1992).Congenital Toxoplasmosis: is screening Desirable? Scand. J. Infect. Dis. 84(Suppl):11-7.

4. Gavinet, M.F. Robert,F. Firtion, G. et al.(1997).congenital Toxoplasmosis due to maternal reinfection during pregnancy. J. Clin. Microbiol. 35: 1276-7. 
5. Guerina, N.et al (1994). Neonatal serologic screening and early treatment for congenital Toxoplasma gondii infection. The new England regional Toxoplasmoșis working group.N. Engl. J.Med. 330:1858-1863

6. Gilbert, R. and Gras, L.(2003).Effect of timing and type of treatment on the risk of mother to child transmission of $\mathrm{T}$. gondi

7. European multicenter study on congenital Toxoplasmosis, V.(110). PP:112-120. Jenum, P. Stray-Pedersen, B.Melby, K. Kapperud, G. Whitelaw, A. Eskid, A. Eng.J.(1998). Incidence of T.gondii infection in 35,940 pregnant women in Norway and pregnancy outcome for infected women. J. Clin. Microbiol. $36:(10), 2900-6$.

8. Jones, J.L. Lopez, A. Wilson, M. Schulkin, J. Gibbs, R.(2001). Congenital Toxoplasmosis: A review.Obstet. Surv.56:296-305.

9. Jones, J.L. Lopez, A. Wilson, M. (2003).Congenital Toxoplasmosis. Am.Fam. Physican . 67: 2131-8.

10. Matrin, F.(2000). Congenital Toxoplasmosis: Value of antenatal screening current prenatal treatment. Rev. Obste. Gynecol.1:46-51.

11. Marua, J.(2013). Bloody serological study of toxoplasmosis in pregnant women and newlyborn babies in Diwanyia, MSc thesis / Alqadisyia University.

12. Moura, F.L. Amendoeira, M.R. Bastos, O.M. Mattos, D.P. Fonseca, A.B. Nicolau, J. L.(2013). Prevalence and Risk factors for T.gondii infection among pregnant and postpartum women attended at public health care facilities in the city of Niteroi state of Rio de Janeiro, Brazil, Rev. Soc. Bras. Med. Trop.46:200-7.

13. Nimri, L. Pelloux, H. and Elkhatib, H. (2004). Detection of T. gondii and specific antibodies in high-risk pregnant women. Am. J. Trop. Med. Hyg. 71 (6):831-5.

14. Paquet, C. Yudin, M.(2013). Toxoplasmosis in pregnancy: Prevention screening and treatment. J. Obest. Gyna, Can. 35: 78-9. 15-

15. Remington, J. Mcleod, R. Wilson, C. Desmonts, G.(2010). Infectious diseases of the fetus and newborn infant. Text book, $17^{\text {th }}$ thed. Pennsylvania: Elsevier. pp:918-1041.

16. Robbins, S. Cotran,R. Kumar, V. (2008). Pathologic Bases of disease. $9^{\text {th }}$ ed. Saunders com., p.373.

17. Schmidt, S. Mazzelia, M. Nixon, R. Mathews, P. (2013). Ab measurement by ELISA methods in Molecular Biology, 849: 507-27. 